\title{
Study on Finding Conflicts and Story Building to Detect Obesity in India
}

\author{
Madhumita Mahapatra \\ Assistant Professor and Research Scholar \\ MRIIRS / Starex University, Haryana
}

\author{
Krishna Kumar Singh, PhD \\ Associate Professor \\ Symbiosis Centre for information Technology, \\ Pune
}

\begin{abstract}
Story building method is one of the most effective method to find solutions of real time problems. Obesity detection and prevention in the context of Indian subjects are prime concern today. Many diseases occur because of long existence of obesity. Obesity rate in India is $3.9 \%$ in respect to $16.6 \%$ average in the world according to world population review. Average overweight population is India is around $16 \%$. But it is growing day by day with larger pace which is great cause of concern. In this paper, researchers used story building method to find different conflicts in the data and provide resolution based on it. After finding conflicts in the data researchers build story on it and proposes solution of detecting and preventing obesity in India. This easiest method to detect and prevent obesity without much knowledge of statistical algorithm. Authors found different key influencers in the data to find factors mostly contributing on obesity in particular type of subject.
\end{abstract}

\section{Keywords}

Storytelling, obesity, visual analytics, conflict finding

\section{INTRODUCTION}

Weight gather mainly takes place over the long run. A great many people realize once they've placed on weight. A part of the warning signs of overweight or stoutness encompass: clothes feeling tight and requiring a larger length, weight acquire when contrasted with past estimation, having additional fats across the middle, a higher-than-everyday weight list (an character's load in kilograms isolated by means of the rectangular of his stature in meters $(\mathrm{kg} / \mathrm{m} 2)$ ) and abdomen outer edge. Other indication might be: breathlessness, expanded perspiring, snoring, again and joint agonies, feeling worn-out in spite of recurring sporting events, lack of ability to adapt to abrupt energetic work, intellectual issues like low self - regard, low fact level, with out appropriate remedy weight can set off unique clinical problems as dyslipidaemia, hypertension, type 2 diabetes, coronary contamination, stroke, osteoarthritis, malignant increase, fruitlessness, rest apnea. Offspring of hefty guardians have in extra of more than one times the danger of offspring of normal weight guardians of getting fats in grownup life. Examinations of youngsters obtained upon entering the sector have proven that familial risk for weight is to a amazing volume hereditary, discovering nearly no connection between's the body masses of embraced youngsters and the masses of their new mother and father, contrasted and a relationship with the loads of their organic guardians that is pretty much as high as the relationship with guardians raising their own kids. The heritability of weight has likewise been reliably adjusted in dual investigations, with heritability gauges surpassing $70 \%$. No matter the reality that there are not many hereditary investigations of overweight or corpulence as such, these examinations likewise demonstrate giant hereditary effect, remembering investigations of both weight and overweight for the cutting-edge instance of youthful twins. Parental corpulence can thusly be applied as a marker of a better hereditary danger of weight for small kids who aren't yet obese, giving the threat to painting the stoutness chance combination before the circumstance is confounded by using the huge wide variety of organic, mental and social effects of heftiness. Because the job of hereditary elements in weight is broadly acknowledged, research has turned towards know-how the contraptions through which genotypes become aggregates. A few examiners have applied examinations between offspring of ordinary weight and overweight guardians to contemplate power stability, awaiting that during excessive-hazard gatherings, either energy use must be low (and admission now not comparably low) or strength intake must be excessive (with out excessive energy use). Unluckily, the outcomes were conflicting. The early perceptions of lower strength intake in babies and offspring of corpulent parents $6 \pm$ eight have no longer been affirmed in later examinations with larger examples. Nine \pm 12 consequences for energy intake had been correspondingly frustrating, with maximum examinations coming across no distinctions in intake,10,12 no matter the fact that there had been ideas that the extent of energy admission from fat may be better in highchance children. Thirteen \pm 15 why need to gatherings of kids who can be dependably expected to save extra fat in the lengthy haul apparently no longer have a greater certain electricity stability? Part of the rationalization for this certainly dumbfounding finding may be that the electricity stability contrasts expected to help the varying weight directions of high-and okay children are minuscule and simply have a blended impact over severa years. Therefore they're tough to distinguish with out profoundly stable measures, endured analyzing and massive instance sizes. Teenagers weight is lots of normal now a days and arising as a giant general medical difficulty of future. All over the global stout children population is growing at a traumatic rate. Identification of corpulence related characters at proper time will assist with making the preventive strides closer to that course. Simply the children weight repute might not be proper to anticipate the corpulence status in grown-up. As most of the people of the corpulent grown-america have been typical during their teenagers days. Solely the author take a look at bmi define to test the well being reputation and formative status. Adiposity rebound (ar) is identified with bmi development among five to 7 years of kids. It would not remember the basic bmi as an alternative thinks approximately some associated additives. This method can assist us expertise the man or woman adjustments and wellbeing chances, because it distinguishes while the adiposity get better shifts its route. Danger of obese is there if an early ar is 
distinguished likewise it conversely recognized with bone age. The early ar saw in typically corpulent instances. The difference in suggest age at ar among fats subjects ( $3 \mathrm{yrs}$ ) and nonfat topics (6 yrs) recommends that those factors paintings right off the bat all through regular lifestyles. Early ar is associated with early low bmi and higher bmi degree after bounce back. This case is incessant in ongoing ages than the previous age. This kind of bmi (at first low and then, at that point high) is connected with metabolic problems like diabetes and coronary coronary heart dieses. Low muscle to fat ratio previous the ar recommends that strength deficiency meals was there in weight-reduction plan at the start phase. In those type of cases kids have been looked after with high protein, low fats ingesting routine though the need became contrary. Mom milk has super belongings of high fats and low protein facilitates the improvement interaction. Weight loss plan admission of the youngster at some point of starting no longer a few years after start impacts the digestion in later piece of existence. Underneath nourishment for the duration of the lethal lifestyles prompts a slow body digestion, that endure in adulthood additionally. Those investigations provide significance to suitable nourishment in teenagers and the food ought to satisfy the dietary prerequisite at various phases of development. As the ar indicates an trade and regular bmi, it has a tendency to be utilized either with the aid of the pediatrician to screen youngster's adiposity and specialists can utilize something very much like decide the obese trouble. It will assist with know-how the continual issue and moreover can recommend preventive measures. (bmi) might be utilized as a sign of heftiness but it is pretty used to foresee portion in children or grown-usain mild of the fact that it neglects to apprehend fats tissue and suit bulk [1]

\section{RELATED WORK}

9 investigations with in extra of 69,000 members met the incorporation measures. The meta-exam showed that breastfeeding reduced the chance of weight in early life altogether. The modified possibilities share changed into 0 . Seventy-eight, ninety five\% ci (zero. Seventy-one, 0. 85) inside the constant model. The supposition of homogeneity of outcomes of the included examinations could not be invalidated (q-check for heterogeneity, $\mathrm{p} 40$. Three), delineated investigations showed no distinctions with reference to various research sorts, age gatherings, which means of bosom taking care of or corpulence and range of jumbling elements adapted to. A portion subordinate impact of bosom looking after term at the commonness of weight changed into accounted for in four examinations. Channel plot relapse gave no signal of distribution predisposition. [13] if each the guardians are hefty and obese, there may be an exceptionally excessive opportunity that the teen will likewise comply with. Presence of parental stoutness is expanding step by step; it's whatever but an interest to follow the power of kids. [5] kids supplied to gdmanalyzed at $£ 26$ weeks' incubation had elevated hypothalamic blood movement (a marker of hypothalamic enactment) in mild of glucose while contrasted and unexposed youngsters, and results stayed after modifications for youngster age, intercourse, bmi, and maternal pre being pregnant bmi. Maternal pre being pregnant bmi turned into decidedly connected with the teen's hypothalamic reaction to glucose. Greater distinguished hypothalamic response to glucose anticipated greater noteworthy expansions in children's bmi 112 months after the truth. [7] an mixture of 75 youngsters (age 7-15 y; sds-bmi +1 . Ninety one- +3 . Eighty one) partook inside the outpatient making ready 'obeldicks' someplace inside the variety of 1999 and 2001. Estimation of stature and weight with out get dressed become acted in all contributors 3 months prior, towards the start of the practise and towards the finish of the education. The participation of children and their oldsters to the mediation conferences of the coaching become excessive $(490 \%)$ other than the dropouts. An combination of 27 children $(37 \%)$ had been fruitless towards the end of the instruction; 20 of those 27 children exited with out completing the training. Every one of the kids who exited failed to lessen their overweight and exited in the initial a $1 / 2 \mathrm{yr}$ of the coaching. $[9,12]$ childhood overweight and stoutness are increasing at a annoying rate for the duration of the sector. 15 a worrying locating is that the sample of expanding corpulence seems to hurry up. 1,24,25 freedman et al24 saw half of greater outstanding yearly expansions in heftiness for the duration of 1983 via 1994 than someplace within the range of 1973 and 1982. An exam of facts from the general public research of wellness and growth 25 utilising the usual offered from cole et al22 noticed an unmistakable sample of overweight and corpulence in english and scottish younger students. The predominance of overweight changed into through and large better in young women. Moreover, there has been a extra noteworthy expansion in extra installed age gatherings. As a result the commonness of obese arrived at almost $20 \%$ inside the most set up scottish young girls in 1994. [2] the bmi is through all debts a precious boundary for epidemiological investigations making use of sex-and agespecific bmi shorts for the inexact arrangement on the extent of heftiness. As the bmi does not permit a dimension of muscle to fat ratio and the dependability of the largeness courting inside the individual pediatric patient is restrained, The author don't suggest bmi for the looking at of treatment in stout children. [6] shetty15 capabilities the extensive shortcomings of past examinations: 'the shortfall of suitable widely delegate statistics and the absence of consistency between investigations of the classi®cation of weight in children restricts our ability to take a gander at both the relative pervasiveness or the commonplace patterns in youth heftiness, each in created and fostering social orders' ( $p 1)$. Kids heftiness isn't an problem in asia and sub saharanafrica. As the food propensity is as but commonplace right here. While the numbers in latinaamerican countries, center east and north africa, european countries and $\mathrm{u}$. S. The quantity are on higher facet. [10] the craving profile of the more chance kids (greater noteworthy inclination for fat, more receptive to meals prompts) may be favorable, or even beneficial, while meals elements are low, but could construct the chance of indulging while food varieties are however enough and tasteful as they appear to be in western industrialized nations these days. It may likewise be safer on every occasion coordinated by using a craving for undeniable levels of lively work, however these results advocate the opposite excessiverisk youngsters favored stationary sports and invested more electricity keen on inactive pursuits, as shown each by time spent at the tv and pc, and figure opinions of movement tiers. [4] cardiovascular danger can greater comfortably foresee making use of weight to stature proportion and associated figures like bmi and pi than the level of bod fat computation in 4-9-12 months-vintage sound children. If there must be an occurrence of girls pi and bmi are same. If there must get up an occurrence of young men bmi predicts the risk factors a long way superior to pi. So in trendy bmi is the maximum valuable to foresee the youth weight as a coming near near wellbeing trouble.[3] extra body weight in youngsters is broadly common in monetarily created countries 1,2 and gives off an impression of being expanding in basically all countries for which records are available. 3 the cutting-edge disbursed report on the predominance of obese and heftiness among 
british youngsters utilising the definitions recommended by means of the international obesity taskforce (iotf) is that of chinn and rona4 which gave figures for 1974-1994. Be that as it could, the state-of-the-art agent review including in extra of 1,000 offspring of each sex is the fitness survey for england 1998,5 and this offers a risk to refresh the previous figures and investigate the facts for styles [11]

\section{FINDING CONFLICTS AND BUILDING STORIES: DATA SOURCES}

Researchers collected data from 600 people from India. Some of them are suffering from obesity and others are inching towards obesity. Height and weight based on gender were collected. According to the BMI and other established factor will be helpful in the initial understanding about the condition of obesity. Data source has 04 variable having2100 total data.

Pre-processing of data: Data collected was inconsistent. Many respondents didn't reply properly due to their own reasons and it causes inconsistency in the data.It required pre-processing of data to make it consistent as per requirements to apply analytical tools. Researchers filled some of blank data by taking average and filling approximated values. Total number of entries of these data is less than $2 \%$. For the better visualization and understanding different conflicts in the data, researcher tool means of all data and saved.

\section{Modelling and Story building:}

Researcher tool help of various statistical charts and show different angles of the story in data. Fig - 01 shows data taken from source and supplied to the widths to draw different charts i.e. Box plot distribution, Bar plot, sieve siagra, mosaic display, line plot, heat map, radviz, linear projection and scattered diagram. Tool adopted is anaconda orange for visualization modelling.

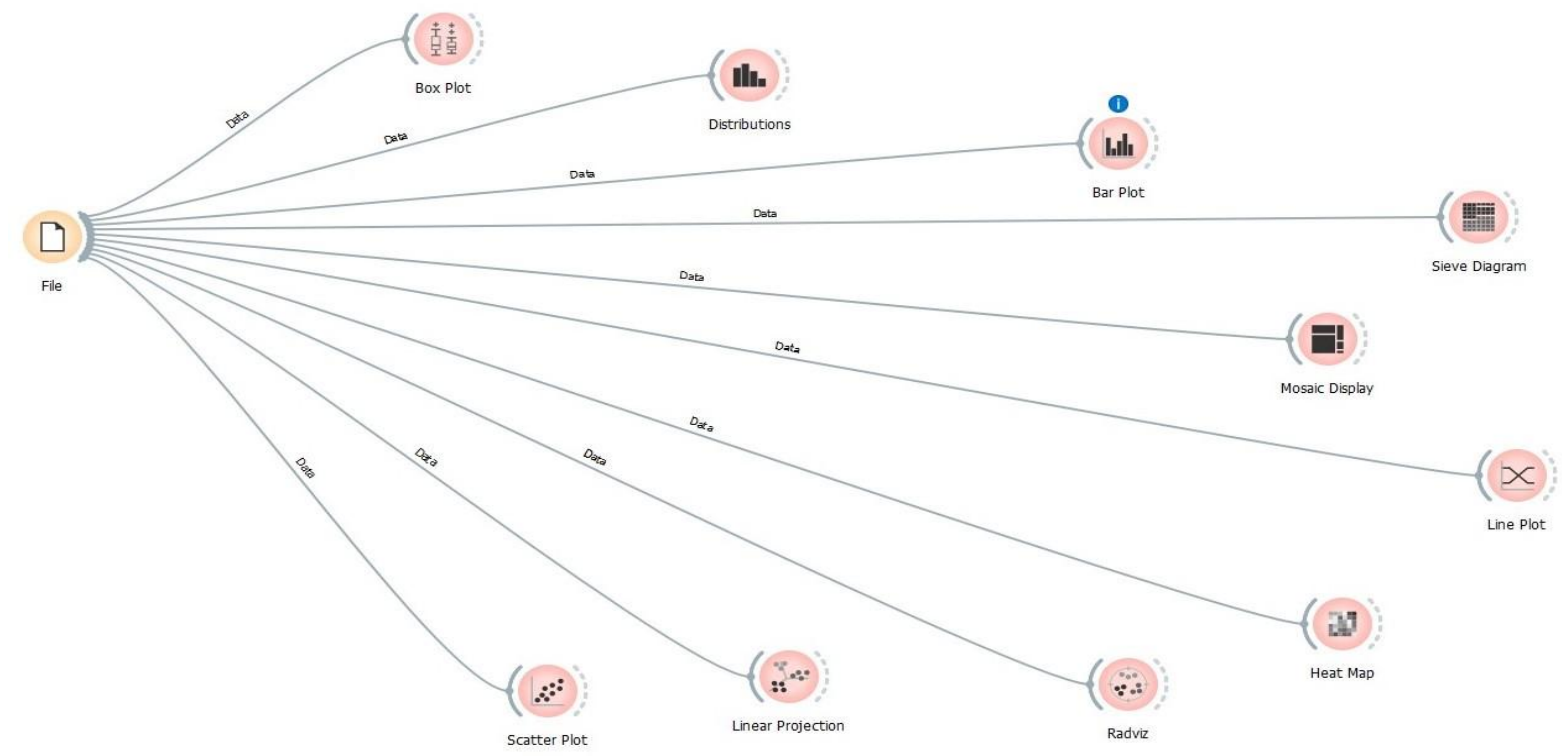

Fig - 01: Modelling 


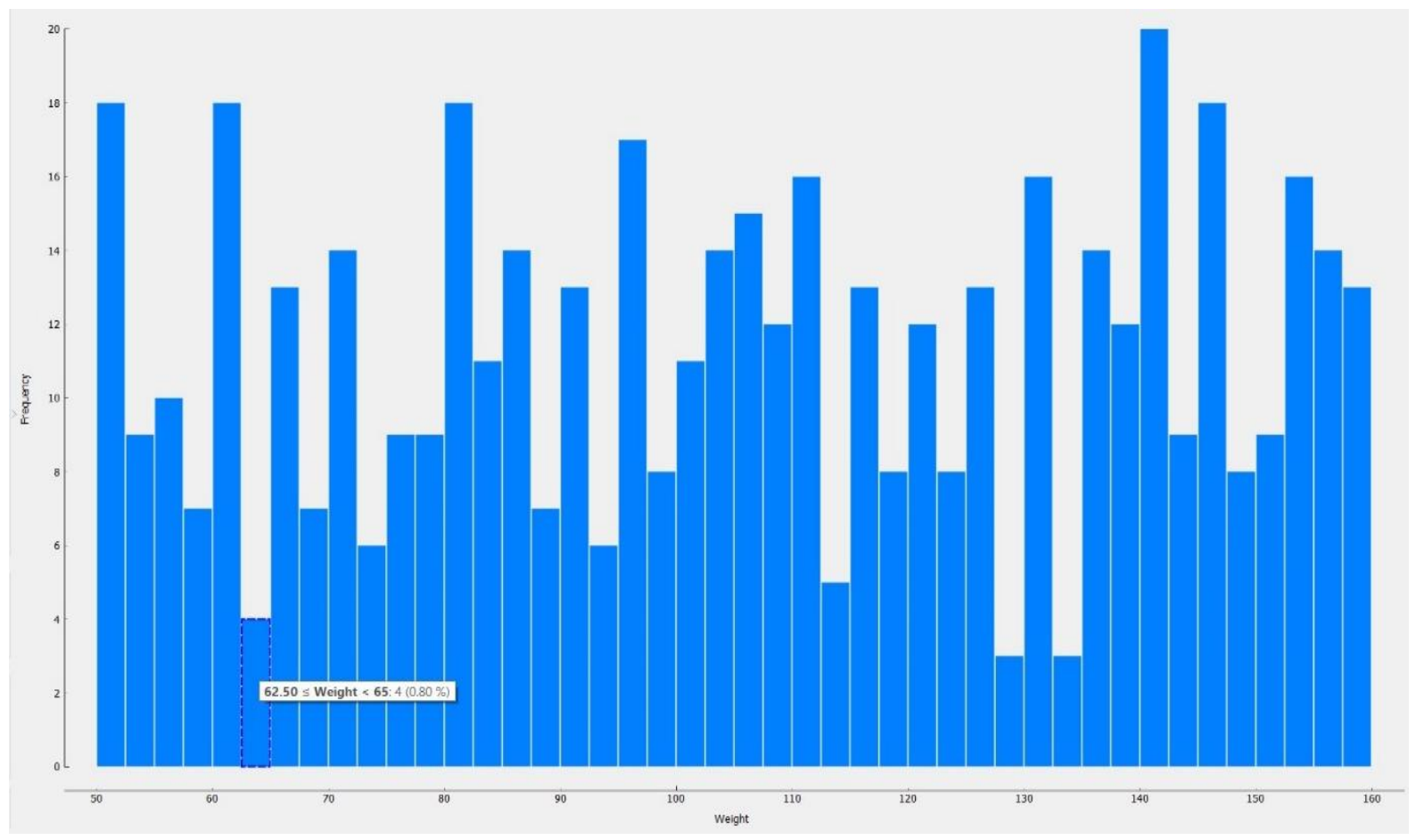

Fig - 02: Distribution based on gender, height and weight

Obesity of a person is not always dependent, as weight increases obesity level may decease or increase depending upon other factors into play as shown in Fig. - 02 (Distribution graph) and Fig - 03 (Bar graph).

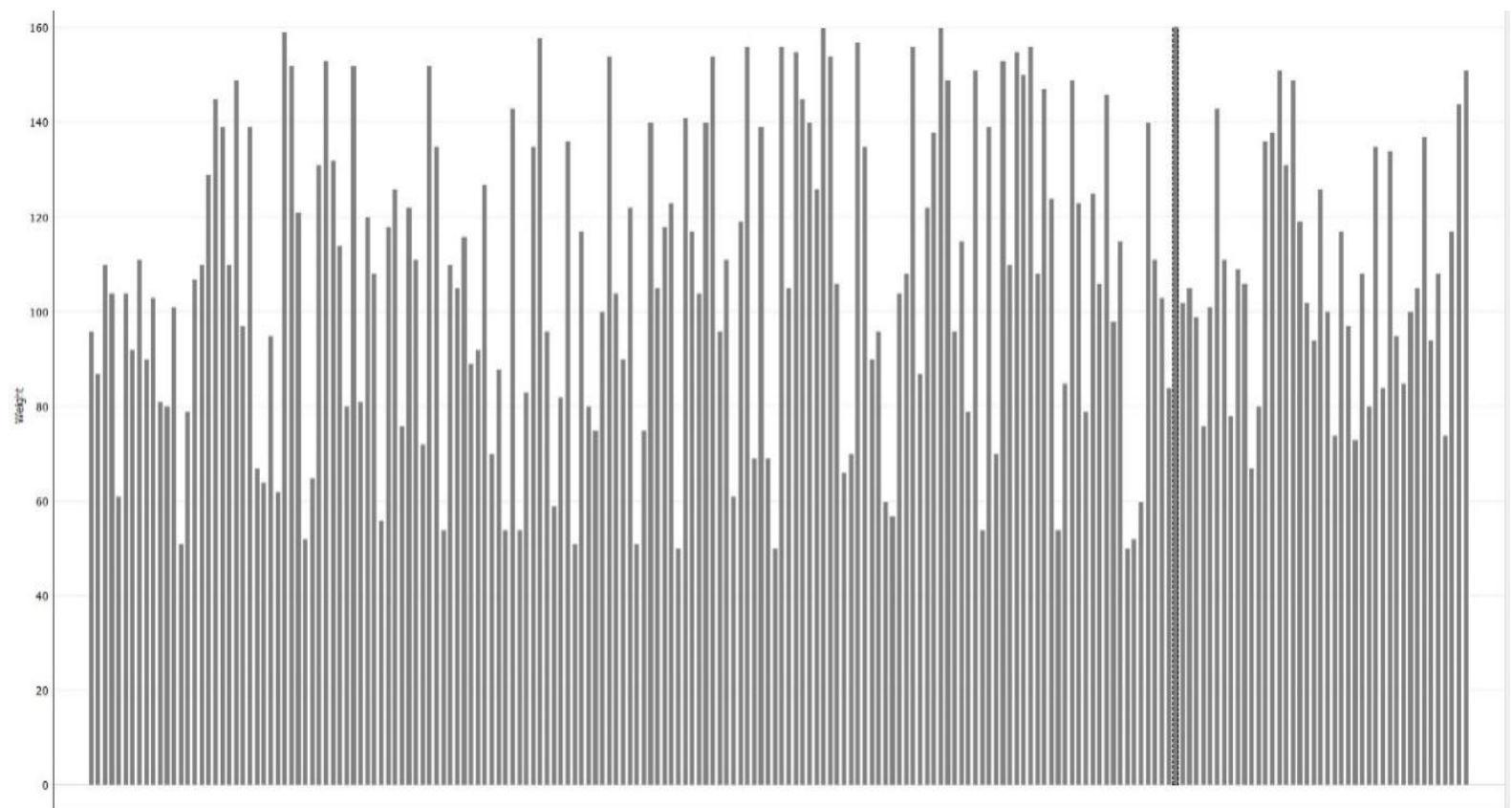

Fig - 03: Bar diagram based on gender, height and weight 


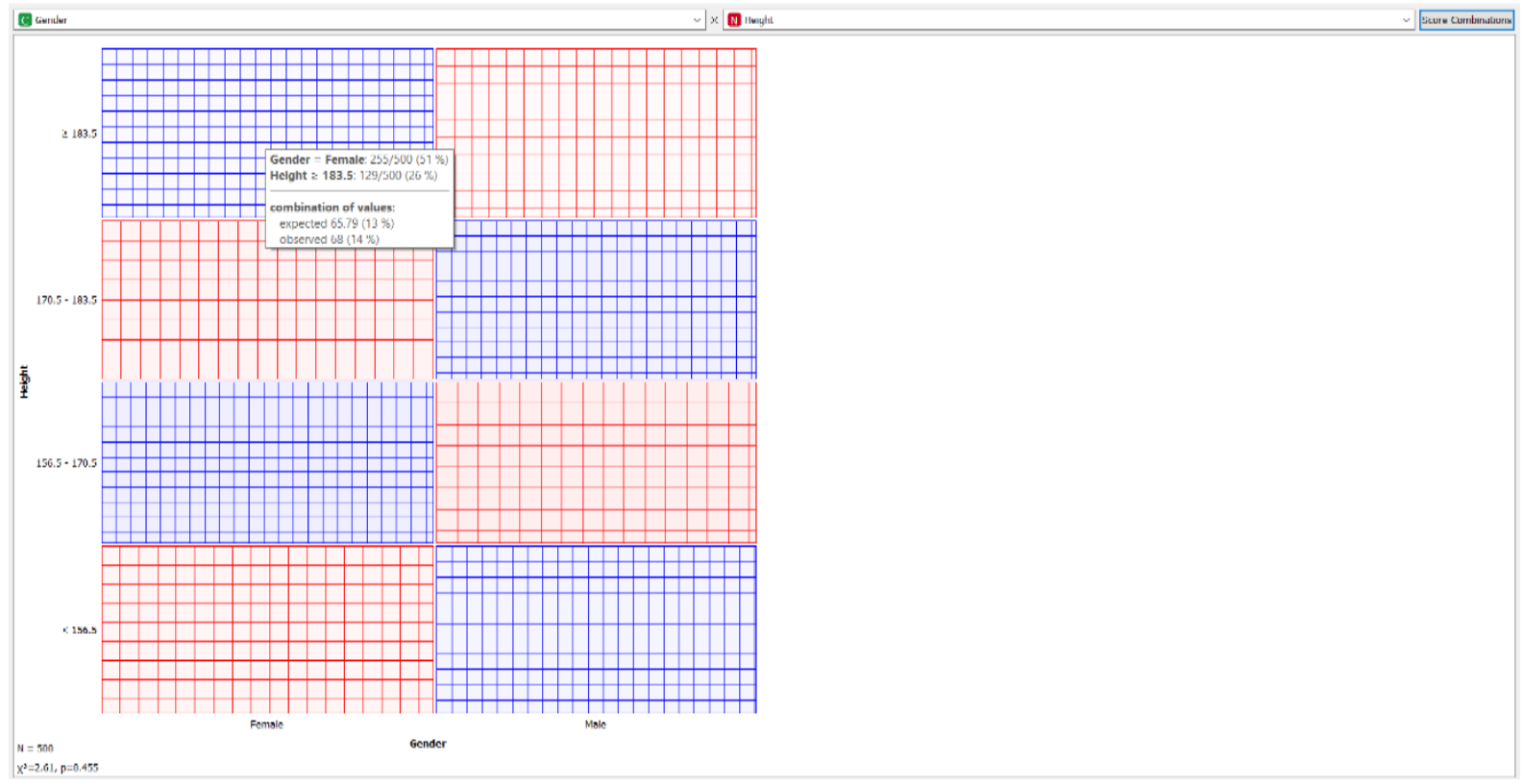

Fig - 04: Sieve diagram based on gender, height and weight

Height of a person is one of the factors into consideration to measure obesity but gender is one of the most crucial factors to find optimum height to decide person's obesity level. In Fig. - 04 and Fig. - 05, with the help of sieve diagram and mosaic diagram, researchers show that with the same height, male obesity level is acceptable where in female's case has different story. In many cases it went reverse. Red colour shows the level of effect because of obesity according to height as per male and female. With height $183.5 \mathrm{com}$, female has value $51 \%$ but male has value more than $65 \%$.

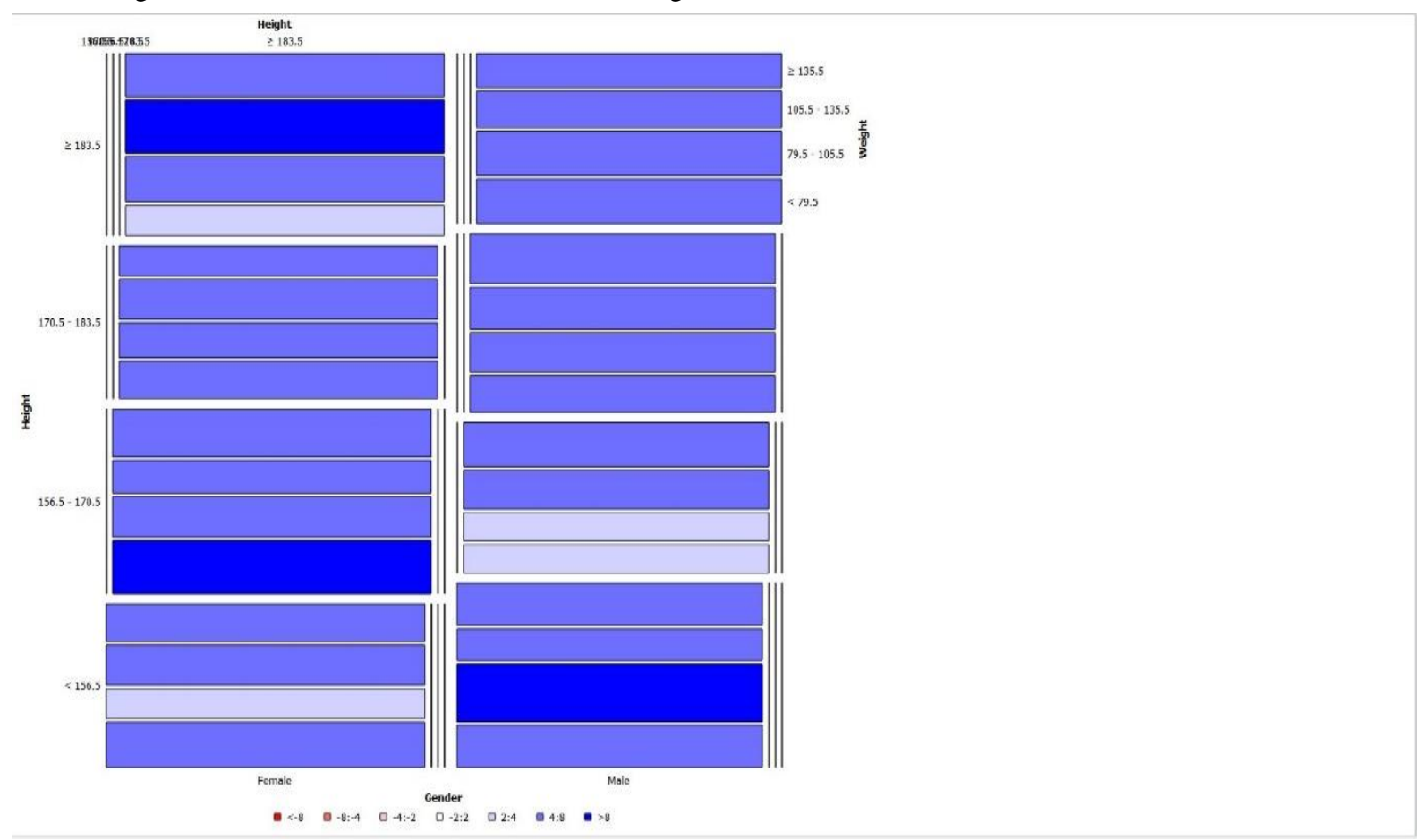

Fig - 05: Mosaic display based on gender, height and weight 


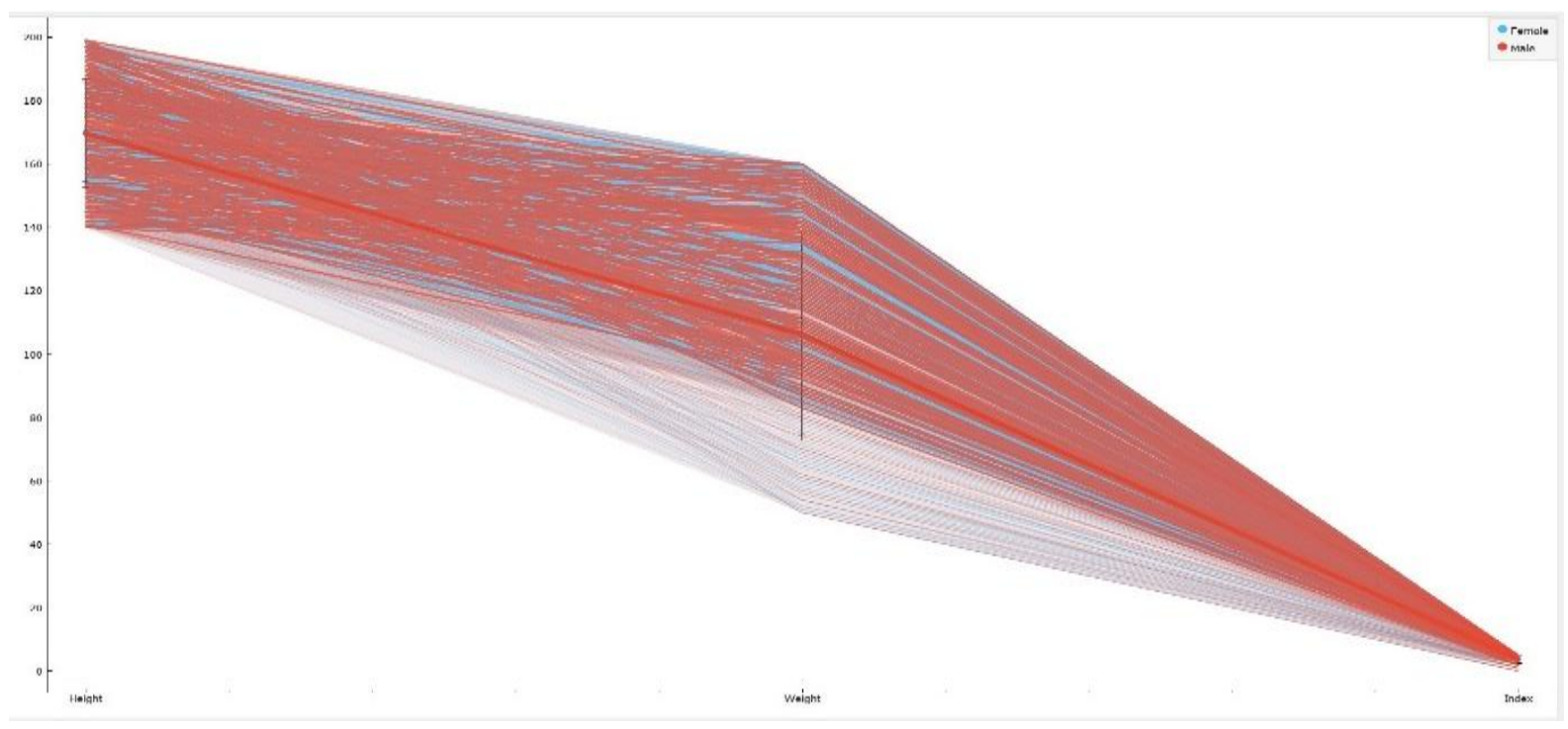

Fig - 06:Line plot based on gender, height and weight

In the above figure (Fig. - 06), data converges in the same manner. Convergence of data in terms of height, weight and index.

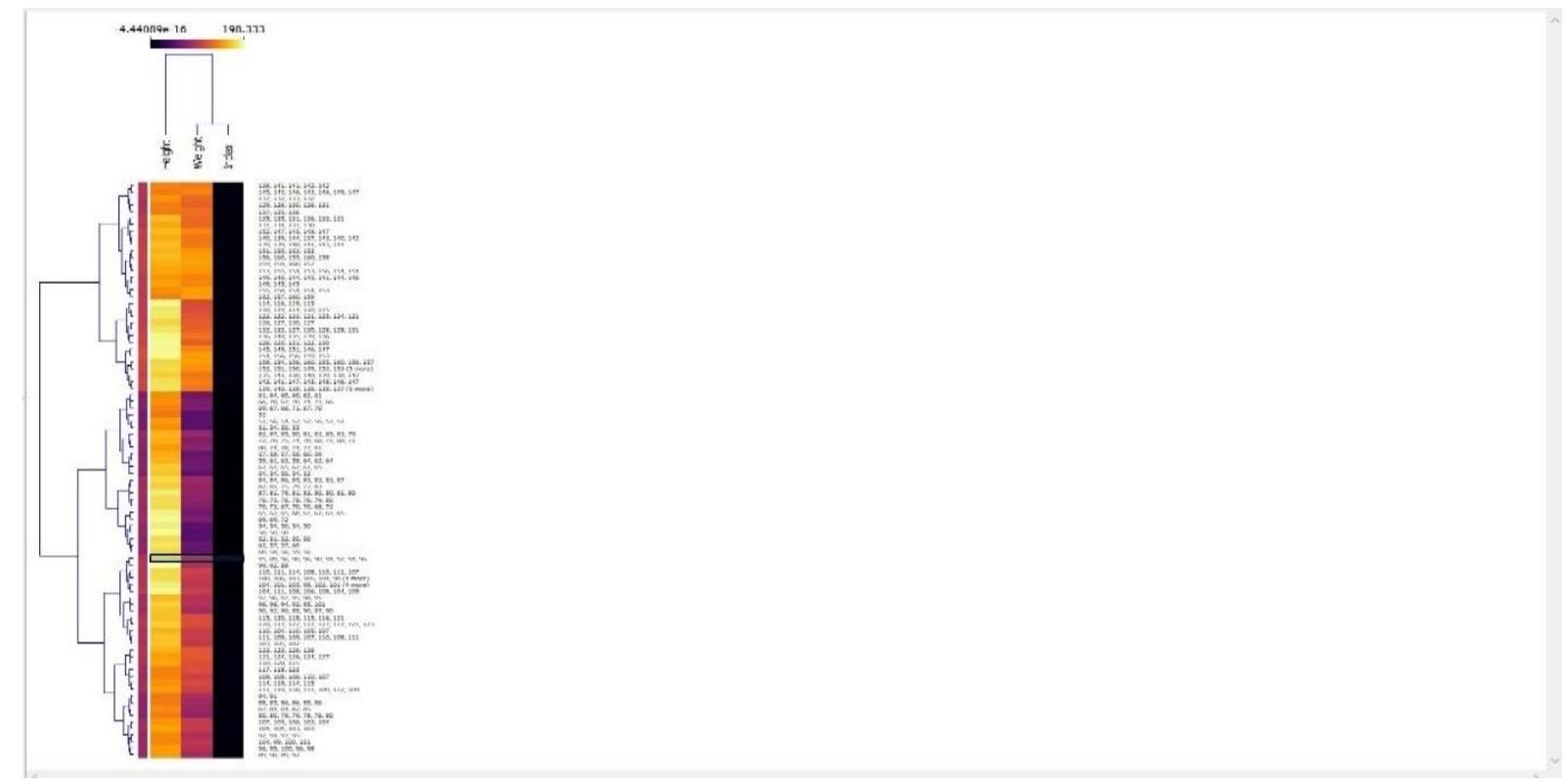

Fig - 07: Heat Map based on gender, height and weight

Clustering based upon obesity status provides us real scenario where people lie in a particular bracket. In Fig - 07 and Fig 08 , with the help of heat map and by considering height, weight and gender researcher able to find different clusters of people based upon their obesity level. 


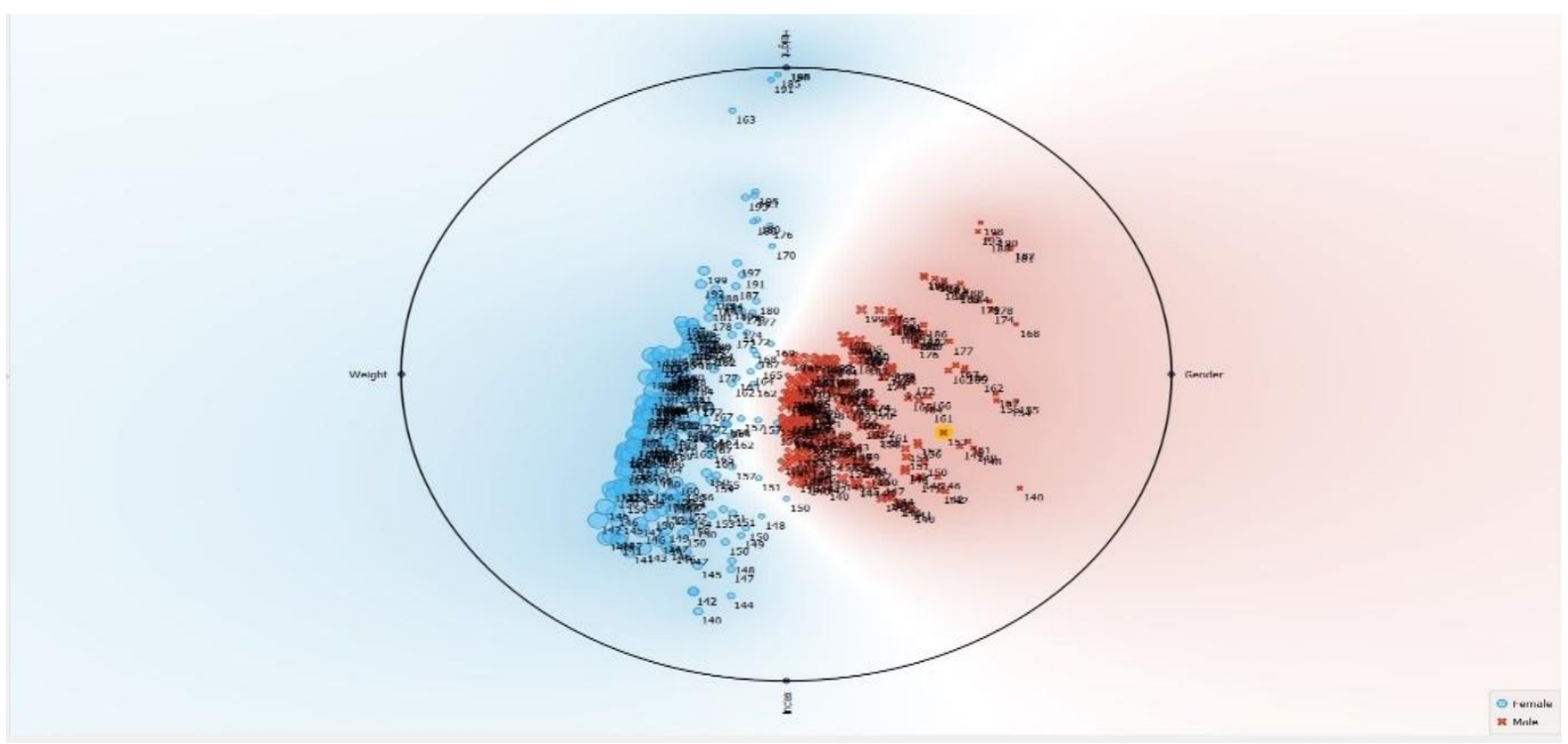

Fig - 08: Radviz based on gender, height and weight

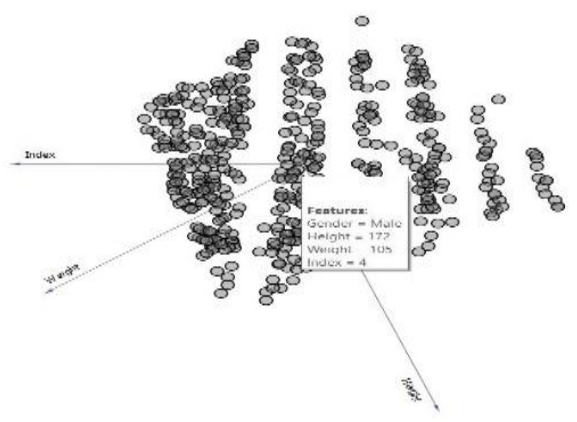

Fig - 09: Linear projection based on gender, height and weight

Linear projection (Fig. - 09) of

three dimensions (i.e., height, weight and gender)show the direction of data and its relevance in finding obesity condition in the area of study. Fig. - 10 to Fig. - 14, shows key influencers on high and low parameters to find out obesity condition in India. Increasing and decreasing order or top segment either high or low factors will contribute to know most key factors or data in the Indian context. It also show key influencers in the clustering and the author can able to find out best possible methods to detect and prevent obesity condition of the country. 


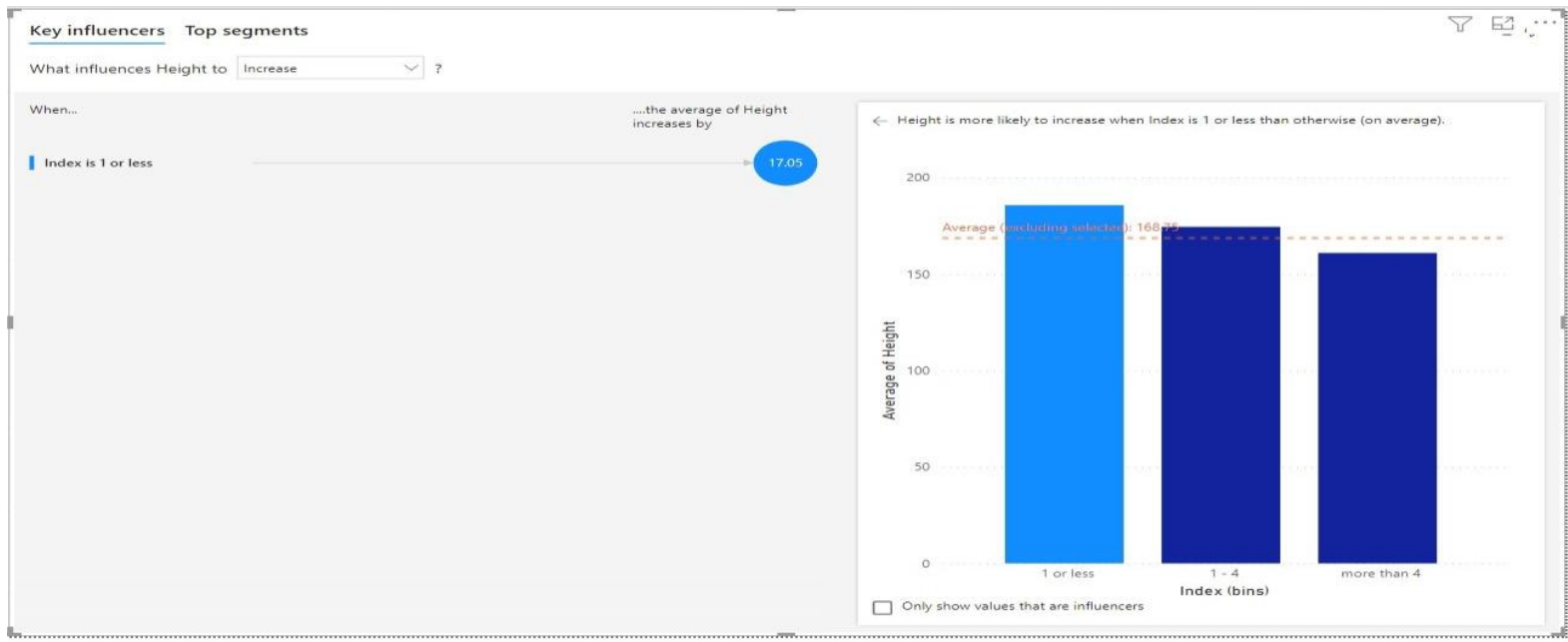

Fig - 10: Finding key influencer in increasing order

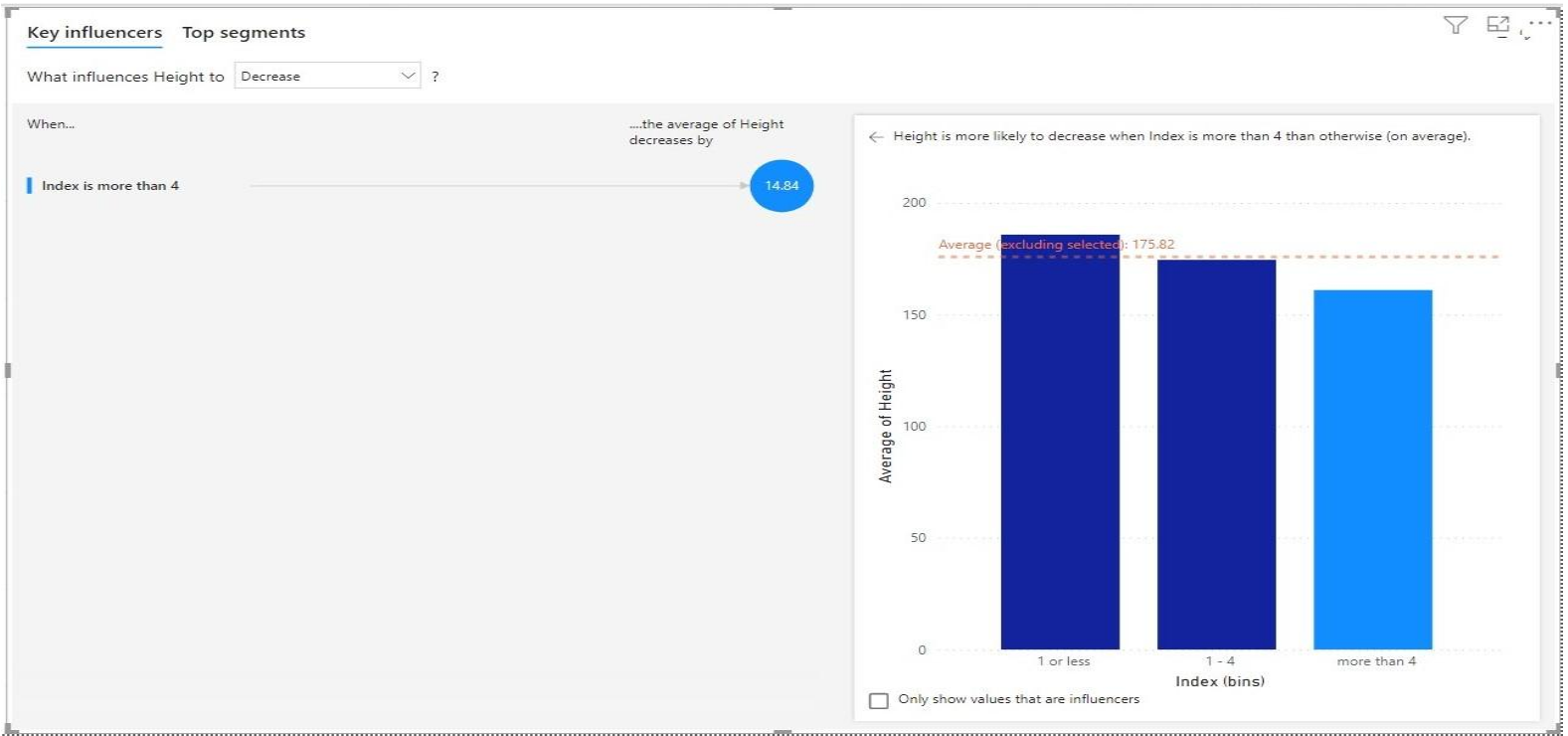

Fig - 11: Finding key influencer in decreasing order

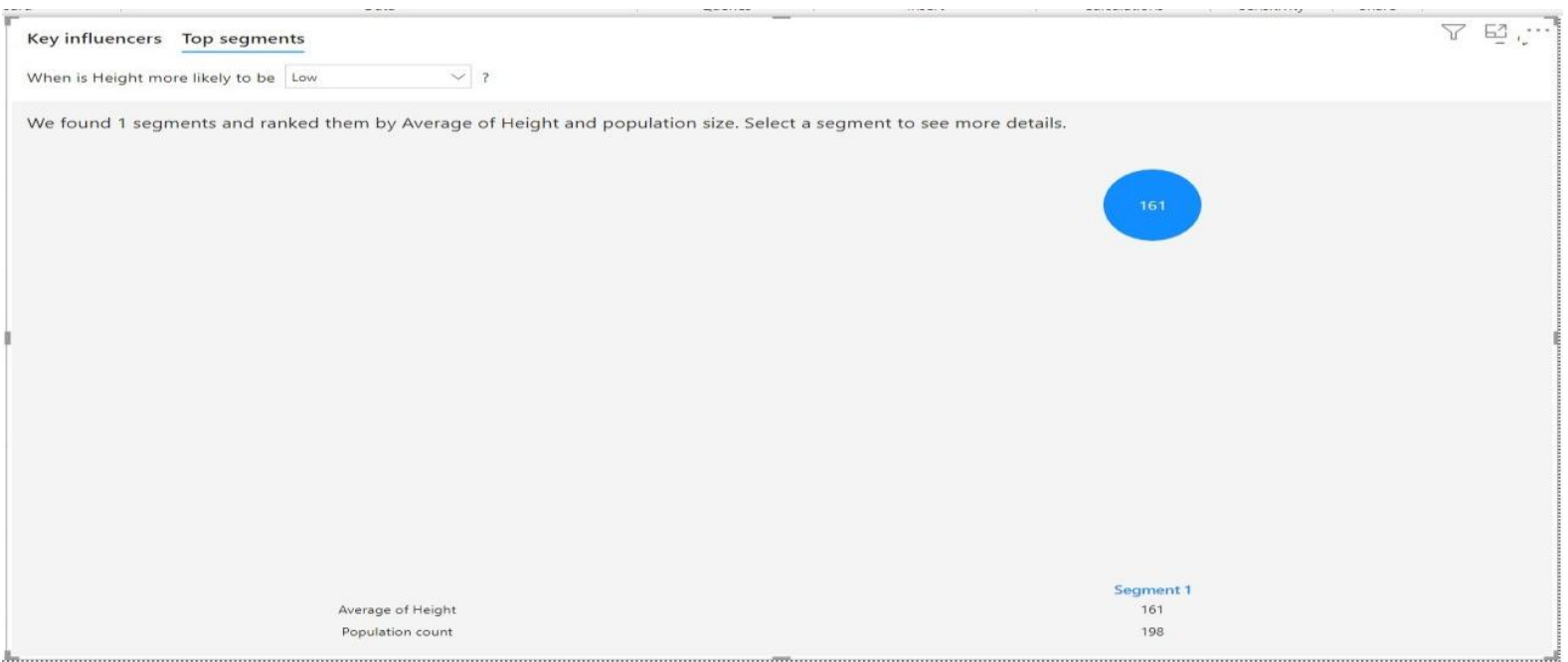

Fig - 12: Height as top segment (Lower end) 


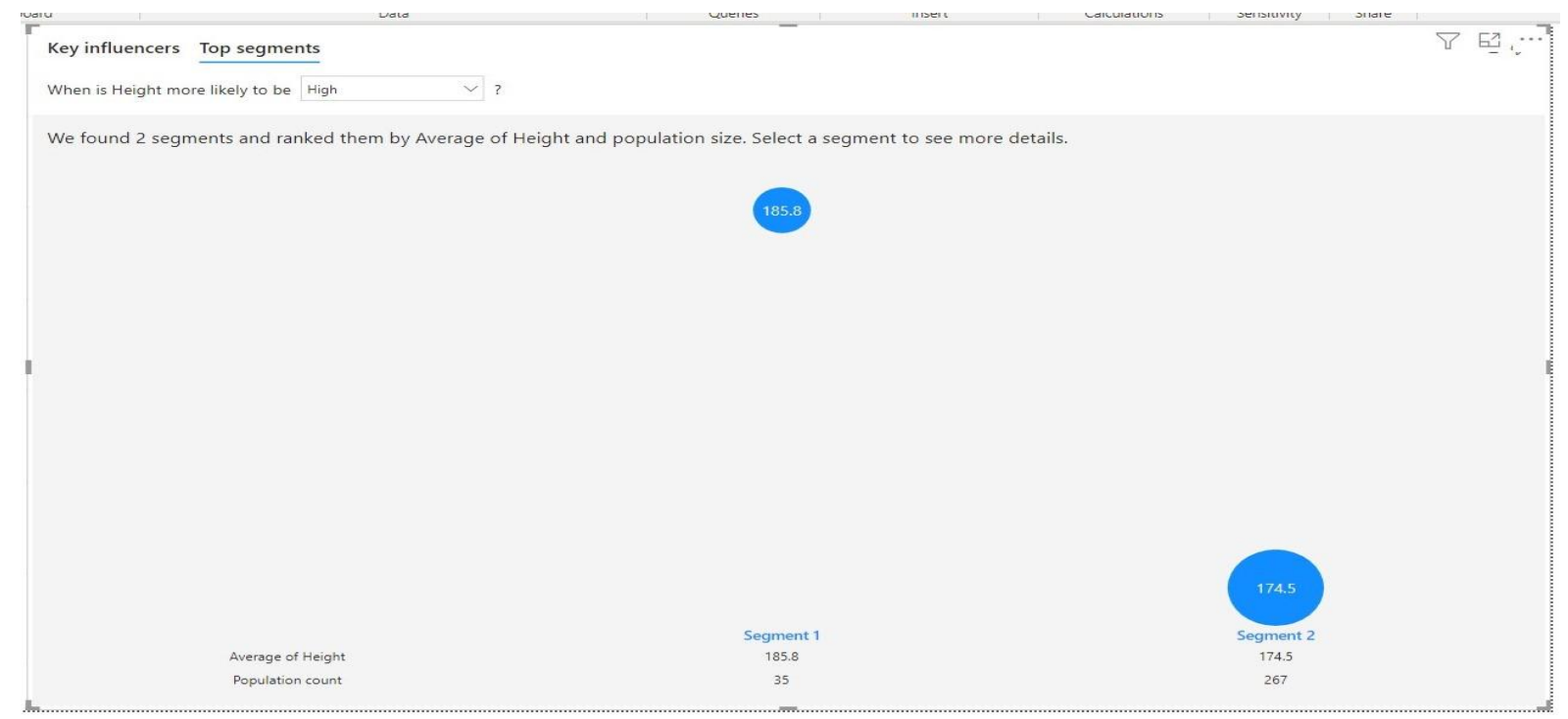

Fig - 13: Height as top segment (Higher end)

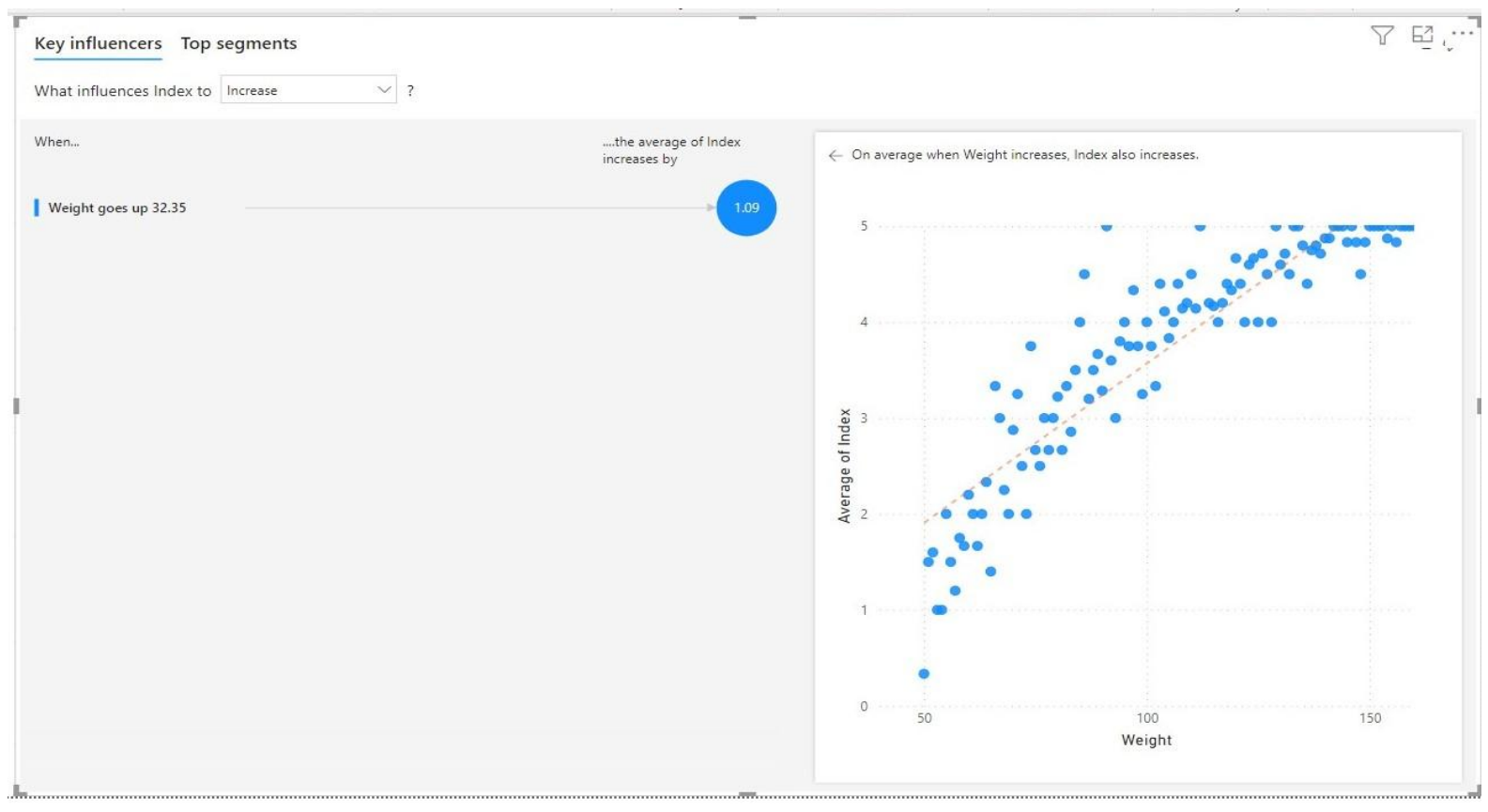

Fig - 14: Weight as key influencer

\section{CONCLUSIONS}

Story telling method is one of the most practiced method to explore various hidden pattern in the data. Conflict finding in the data and providing resolution played a key role in detecting and preventing obesity in this case. Above methodology tried to find out different conflicts in the data and its key influencer in the study of obesity in India. In this research authors build stories by considering various factors of subjects. Key influencer of each subject plays vital role in conflict finding and providing resolution.

\section{REFERENCES}

[1] Anderson, Brian J., and Nick HG Holford. "Getting the dose right for obese children." (2017): 54-55.

[2] Frye, C., and J. Heinrich. "Trends and predictors of overweight and obesity in East German children." International journal of obesity 27 , no. 8 (2003): 963-969.

[3] Geiss, H.C., Parhofer, K.G. and Schwandt, P., 2001. Parameters of childhood obesity and their relationship to cardiovascular risk factors in healthy prepubescent children. International Journal of Obesity, 25(6), pp.830837.

[4] Wardle, J., Guthrie, C., Sanderson, S., Birch, L. and Plomin, R., 2001. Food and activity preferences in children of lean and obese parents. International journal of obesity, 25(7), pp.971-977.

[5] Lake, Julie K., Chris Power, and Tim J. Cole. "Child to adult body mass index in the 1958 British birth cohort: associations with parental obesity." Archives of disease in childhood 77, no. 5 (1997): 376-380. 
[6] Widhalm, K., K. Schönegger, C. Huemer, and A. Auterith. "Does the BMI reflect body fat in obese children and adolescents? A study using the TOBEC method." International Journal of Obesity 25, no. 2 (2001): 279-285

[7] Page, Kathleen A., Shan Luo, Xinhui Wang, Ting Chow, Jasmin Alves, Thomas A. Buchanan, and Anny H. Xiang. "Children exposed to maternal obesity or gestational diabetes mellitus during early fetal development have hypothalamic alterations that predict future weight gain." Diabetes Care 42, no. 8 (2019): 1473-1480.

[8] Singh, Krishna Kumar, PritiDimri, and Madhu Rawat. "Green database model for stock market: a case study of Indian stock market." In 2014 5th International Conference-Confluence The Next Generation Information Technology Summit (Confluence), pp. 848853. IEEE, 2014

[9] Rolland-Cachera, M. F., M. Deheeger, M. Maillot, and F. Bellisle. "Early adiposity rebound: causes and consequences for obesity in children and adults." International journal of obesity 30, no. 4 (2006): S11-S17.

[10] Martorell, R., L. Kettel Khan, M. L. Hughes, and L. M. Grummer-Strawn. "Overweight and obesity in preschool children from developing countries." International journal of obesity 24 , no. 8 (2000): 959-967.

[11] Lobstein, T. J., W. P. T. James, and T. J. Cole. "Increasing levels of excess weight among children in England." International journal of obesity 27, no. 9 (2003): 1136-1138.

[12] Reinehr, T., K. Brylak, U. Alexy, M. Kersting, and W. Andler. "Predictors to success in outpatient training in obese children and adolescents." International journal of obesity 27, no. 9 (2003): 1087-1092.

[13] Arenz, Stephan, R. Rückerl, BerthodKoletzko, and Rudiger von Kries. "Breast-feeding and childhood obesity - a systematic review." International journal of obesity 28, no. 10 (2004): 1247-1256. 